\title{
Do children with autism re-enact object movements rather than imitate demonstrator actions?
}

Deborah M. Custance ${ }^{1}$, Jennifer L. Mayer ${ }^{2}$, Emmelianna Kumar, Elisabeth Hill ${ }^{1}$, \& Pamela F. Heaton ${ }^{1}$

\begin{abstract}
It has been suggested that autism-specific imitative deficits may be reduced or even spared in object-related activities. However, most previous research has not sufficiently distinguished object movement reenactment (learning about the ways in which object move) from imitation (learning about the topography of demonstrated actions). 20 children with autism (CWA) and 20 typically developing children (TDC) were presented with puzzle-boxes containing prizes. Test-objects and experimental conditions were designed to isolate object- and action-related aspects of demonstrations. There were four types of video demonstrations: 1) a full demonstration by an adult; 2) a ghost demonstration with object movements alone; 3) mimed solutions demonstrated adjacent to the objects and 4) random actions performed on the surface of the objects. There were no significant between-group differences in the degree to which CWA and TDC matched the full demonstrations, the actual demonstrations, or in their times to first solution in any of the conditions. Although there was no clear imitative deficit in the CWA, regression analyses were conducted to explore in more detail whether diagnosis, VIQ, NVIQ, age or motor coordination predicted performance. The results are discussed in relation to the use of extrinsic versus intrinsic rewards and the interplay between motor coordination and the relative rigidity versus pliability of objects.
\end{abstract}

Keywords: autism, imitation, emulation, transitive

${ }^{1}$ Goldsmiths College, Department of Psychology, 8 Lewisham Way, New Cross, London SE14 6NW, UK. Fax: +44 (0)20 7919 7873, Emails: d.custance@gold.ac.uk, e.hill@gold.ac.uk, p.heaton@gold.ac.uk Jennifer L. Mayer, University of Roehampton, Department of Psychology, Whitelands College, Holyborne Avenue, London, SW15 4JD, Email: Jennifer.mayer@roehampton.ac.uk ${ }^{3}$ Emmelianna Kumar, Institute of Zoology, Zoological Society of London, Regent's Park, London, NW1 4RY, Email: emmelianna.kumar@ioz.ac.uk

CORRESPONDING AUTHOR: Jennifer L. Mayer, University of Roehampton, Department of Psychology, Whitelands College, Holyborne Avenue, London, SW15 4JD, Email: Jennifer.mayer@roehampton.ac.uk

GRANT SPONSOR: Economic and Social Research Council (award reference number RES-00022-2006)

* This is a preprint of an article published in: Custance, D. M., Mayer, J. L., Kumar, E., Hill, E., \& Heaton, P. F. (2013). Do Children With Autism Re-Enact Object Movements Rather Than Imitate Demonstrator Actions? Autism Research, 1-12. doi:10.1002/aur.1328 http://onlinelibrary.wiley.com/doi/10.1002/aur.1328/abstract 
Object-related imitation in autism

http://onlinelibrary.wiley.com/doi/10.1002/aur.1328/abstract 


\section{Introduction}

Autism is a neurodevelopmental disorder diagnosed on the basis of impairments in social interaction, communication and by restricted and repetitive behavior (DSM-IV-TR, APA 2000). Imitation is a quintessentially social activity and it is unsurprising that clinical observations and experimental studies suggest that children with autism (CWA) rarely spontaneously imitate the actions of others (e.g., Ingersoll 2008; Receveur et al. 2005). Indeed, the large majority of rigorously designed studies investigating action imitation in autism have revealed deficits (Rogers, 1999; Williams et al. 2004).

The issue of imitation in autism is important because it has been suggested that an imitative deficit could trigger an abnormal developmental cascade (Rogers \& Pennington 1991). Imitation may be essential for the development of normal selfother differentiation (Meltzoff 2005), psychological identification (Hobson \& Lee 1999) and theory of mind (Meltzoff \& Gopnik 1993; Perra et al. 2008). However, the precise nature and basis of the imitative deficit in autism is hotly debated. There is considerable controversy about whether imitation should be considered a core deficit in terms of being "unique to autism, specific and universal" (Vanvuchelen et al. 2011, p. 90). Some researchers argue that the imitative deficit is based upon a faulty perceptual-motor system (e.g. Vanvuchelen et al. 2007) or more precisely a faulty mirror neuron system (Williams et al. 2001) whilst others contest these suggestions (e.g. Hamilton et al. 2007). In contrast, it has also been argued that the imitative deficit in autism is based primarily upon socio-communicative problems (e.g. Zachor et al. 2010), reduced psychological identification with others (e.g. Hobson \& Lee 1999) or reduced social engagement (Rogers et al. 2010).

Deficits in performance on imitation tasks may also, at least in part, be due to poor motor control (e.g., McDuffie et al. 2007). Dyspraxia is a disorder of skilled intentional movements that is not caused by specific motor abnormalities. Several studies have reported elevated levels of dyspraxia in CWA (Fournier et al. 2010), as well as more general motor difficulties consistent with a diagnosis of developmental coordination disorder (American Psychiatric Association, 2000; Bhat et al. 2011). However other studies have failed to observe a significant correlation between motor coordination and imitative ability in CWA (e.g. Young et al., 2010) and the association between these disabilities clearly merits further study.

Although most researchers agree that there is a deficit in imitation in CWA ( $c f$ Bird et al. 2007), Williams et al. (2004) point out that the results from previous research seem to indicate that imitative ability may be reduced or even spared in the context of object-related activities. However, they also suggest that object-related responses in CWA may reflect processes that are not truly imitative. This highlights the importance of distinguishing imitation and other social learning processes in studies of object-related imitation. Thus, one of the main aims of the present study was to investigate whether CWA rely on certain kinds of non-imitative social learning processes more than TDC do.

Three processes are of particular relevance to the present study: imitation, a form of emulation called object movement reenactment (OMR) and local enhancement. Here, imitation is defined as learning about the topography of a demonstrator's actions (Whiten \& Ham 1992). Although an observer may read the intentions underlying demonstrated actions, we do not include intention-reading as a necessary component of imitation, rather an adjunct to it (see Heyes 1993 for a similar approach). Local enhancement involves an observer's attention being brought to 
salient parts of an object by a demonstrator: thereafter, any behavioural similarity between demonstrator and observer is coincidental (Spence 1937).

There are several different kinds of emulation (Whiten et al. 2004). Autism researchers have tended to focus on "goal emulation" (e.g., Rogers et al. 2010) in which an observer achieves the same goal as demonstrated using different behavioral means (Call \& Carpenter 2002). Although goal emulation is of great scientific interest, we set out to investigate a different type of emulation: object movement reenactment (OMR, Custance et al 1999). OMR has been studied in animals and typically developing children (TDC) (e.g., Fawcett et al. 2002; Tennie et al. 2006; Hopper et al. 2011) but not, as far as we are aware, in CWA. It involves learning via observation about the ways in which objects move. It has been empirically distinguished from imitation by using "ghost displays" in which presented objects appear to move independent of an external agent (see Hopper 2010 for a review). Most studies have found that TDC exhibit enhanced learning after watching a human demonstrator compared to when they watch "ghostly" object movements alone (Subiaul 2011).

According to these definitions, OMR and local enhancement are essentially object-oriented, whilst imitation is more person-oriented. Since CWA tend to be less socially-oriented than TDC, one might expect them to show a comparatively lower tendency to copy the precise topography of a human demonstrator's actions (i.e., imitate). However, one would expect them to perform equally well when all a demonstrator does is bring specific objects to their attention (i.e., learn via local enhancement) or when they watch the disembodied movements of objects (i.e., learn by OMR). Without careful experimental controls, it is often impossible to tell which aspect of an object-related demonstration an observer has focused upon when they themselves come to manipulate objects. Due to this problem, test-objects and experimental conditions were designed to isolate object- and action-related aspects of demonstrations. CWA and TDC were presented with six different puzzle-boxes. Each puzzle-box could be opened using specific actions to gain an extrinsic reward (i.e. stickers or toys). In order to see how children would respond to different aspects of a demonstration, participants were shown one of four types of demonstration: 1) a full demonstration by an adult; 2) a ghost demonstration with object movements alone; 3 ) mimed solutions demonstrated adjacent to the relevant parts of the objects and 4) random actions performed on the surface of the objects to see if children could reach the solution by means of local enhancement alone.

On four puzzle objects (lip-lock, fishing-tube, dome and levers) both object movements and demonstrator actions were visible in full demonstrations. If CWA learn principally via OMR, there should be no difference between their performance on full and ghost demonstrations for these test-objects since they could see the object movements in both conditions. If they do differ from TDC in having a stronger tendency to learn by OMR than by imitation, they would be less likely to incorporate useful aspects of the demonstrators' actions into their own problem-solving and this may result in reduced copying of the topography of the demonstrator's actions and slower times to solution.

On the two remaining puzzle-boxes (button and bolts), imitation was further distinguished from OMR by obscuring aspects of object movements. In full demonstrations, the rotational movements of the bolts and rotations followed by depressions of the button were obscured by demonstrator hand actions. If children in the full condition copied button turning and pressing or bolt-twisting, then they could only do so via imitation, since no object movements were available to them. 
We hypothesize that in contrast to TDC, CWA have a higher tendency to learn from non-social aspects of an object-related demonstration and predict that: 1) CWA will show a reduced tendency to imitate in the full and mime conditions compared to TDC; 2) CWA will exhibit a lower tendency compared to TDC to copy actions in full demonstrations where associated object movements are obscured and they will also take significantly longer to solve these puzzles; 3) CWA will show a higher tendency in the ghost condition to turn and press the button and twist the bolts than in the full condition because object movements will be more salient to them than demonstrator actions. The opposite pattern will be evident in TDC; 4) there will be no significant difference in the degree to which CWA match full demonstrations or how long they take to solve puzzle-objects in full and ghost conditions for those puzzles in which object movements are not obscured by the demonstrator. In contrast, TDC will match significantly more and solve these puzzle-boxes faster in the full versus ghost condition; and 5) all children will learn least from watching random actions, although CWA might be more likely to ignore random actions and devise their own solutions than TDC.

\section{Participants}

\section{Method}

Twenty-seven children from four specialist autism schools in the UK were recruited. Prior to admittance to these schools children received rigorous assessment by an autism specialist. To confirm diagnosis, we administered the Developmental, Dimensional and Diagnostic Interview (3Di) (Skuse et al. 2004). The 3Di correlates highly with the Autism Diagnostic Observation Schedule (Lord et al. 2000) and the Autism Diagnostic Interview - Revised (Lord et al. 1994). One child was excluded because the 3Di failed to return a diagnosis of autism. Two children moved school; two others were excluded because their verbal IQ (VIQ) did not register on the standard BPVS scale. Finally, two children failed to settle during testing. The final sample of 20 CWA ( 17 boys; 3 girls, mean age $=10: 4, \mathrm{SD}=2: 4)$ all fell within the mid to low range of autistic severity in each of the subscales of the 3Di (Table 1).

Sixty-two children from four mainstream schools were screened in order to identify 20 TDC who matched the CWA in terms of age and IQ (Table 1). VIQ was measured using the short form of the British Picture Vocabulary Scale (BPVS, Dunn et al. 1997). In addition, since many of the presented tasks involved novel problemsolving, and the Raven's Matrices (Raven et al. 1998) is a particularly good test of fluid intelligence for CWA (Dawson et al. 2007), this test was used for matching on non-verbal intelligence (NVIQ). A final sample of 16 boys and four girls (mean age $=10: 4, \mathrm{SD}=2: 5$ ) was selected. There were no significant differences between the CWA and TDC groups on age $(\mathrm{t}=.039$, $\mathrm{df}=38, \mathrm{p}=.969)$, VIQ $(\mathrm{t}=-1.298, \mathrm{df}=38$, $\mathrm{p}=.202)$ or Raven's scores $(\mathrm{t}=-.419, \mathrm{df}=38, \mathrm{p}=.678)$. The VIQ of nine CWA fell within 1+/-SD of the population standardised mean (85-115), eight were within 2SD (i.e., between 84-70) and three children fell below 2SD. Eleven TDC fell within 1+/SD of the mean, eight fell below 2SD and one child was over 2SD above the mean.

\section{INSERT TABLE 1 HERE}

\section{Motor coordination}

As the effect of motor coordination on the imitative ability of CWA was not the main focus of our research, more comprehensive and time-consuming 
standardized motor coordination batteries such as the Bruininks-Oseretskey Test (Bruininks \& Bruininks 2005) or The Movement Assessment Battery for Children (Henderson et al. 2007) were not used. Instead, two simple tests of motor coordination were developed for use in the experiment. 1) Peg-board - participants were asked to move 10 pegs from an upper set of holes on a wooden board to a parallel lower set as quickly and accurately as possible; once with each hand. 2) Buzzwire - participants were asked to pass a metal hoop along an arced length of wire without making contact; once with each hand. If the hoop touched the wire, it completed a circuit and beeped.

The first author scored the peg-board and buzz-wire trials and a second observer, who was unaware of the study's hypotheses and participant diagnosis, scored trials from a random selection of four CWA and four TDC (i.e., 20\% of each group). High inter-observer agreement was achieved (peg-board errors $\mathrm{r}=.831, \mathrm{p}=.01$ and times $\mathrm{r}=.897, \mathrm{p}=.003$; buzz-wire errors $\mathrm{r}=.899, \mathrm{p}=.002$ and times $\mathrm{r}=.941$, $\mathrm{p}<.001)$. There were no significant differences between CWA and TDC in mean time taken to complete each trial: peg-board $(\mathrm{t}=.954, \mathrm{df}=38, \mathrm{p}=.346)$ and buzz-wire $(\mathrm{t}=1.85, \mathrm{df}=35, \mathrm{p}=.073)$. However, CWA produced significantly more errors than TDC on both tasks (peg-board $\mathrm{t}=.328, \mathrm{df}=38, \mathrm{p}=.002$; buzz-wire $\mathrm{t}=3.21, \mathrm{df}=35$, $\mathrm{p}=.003$ ). Therefore, in line with previous research, our sample of CWA exhibited lower motor coordination than age and IQ matched TDC.

\section{Materials}

1. Button box (D'Sousa 2004, Figure 1a, $25 \mathrm{cmX} 25 \mathrm{~cm} X 25 \mathrm{~cm}$ ) had a circular well $(10 \mathrm{cmX} 4 \mathrm{~cm})$ in its top surface with a transparent lid. The lid automatically swiveled open when three turns followed by three presses were applied to a protruding steel button ( $6 \mathrm{~cm}$ in diameter) mounted on the box's front wall.

2. Levers box (Figure $1 \mathrm{~b}, 20 \mathrm{~cm} \times 30 \mathrm{~cm} X 15 \mathrm{~cm}$ ) had a hinged lid held shut from inside by two catches attached to a pair of levers (20 $\mathrm{cm}$ apart) protruding from its front wall and a magnet latch. The levers had to be held down simultaneously and then a small amount of force was needed to release the magnet catch and open the lid. In the full condition, the demonstrator pressed the levers with her forearm and then used her free hand to lift the lid.

3. Dome box (Figure 1c, $15 \mathrm{cmX} 15 \mathrm{cmX} 15 \mathrm{~cm}$ ) was based on a task invented by Meltzoff (1985; see also Gergeley et al. 2002). Our version had a hinged front wall held shut with a magnet-lock. There was a metal button on its top surface covered by a partially transparent soft plastic dome. The hinged wall would only fall open when the experimenter released the magnet-lock by pressing a hidden button. The button was pressed only when a participant rested their forehead on the dome.

4. Lip-lock box (Whiten et al. 1996, Figure 1d, $14 \mathrm{cmX} 16 \mathrm{cmX} 12 \mathrm{~cm}$ ) had a hinged lid held shut by a T-shaped lock with a lip that extended over the front edge of the box-lid. The lock was disabled by rotating a non-threaded pin four times before removal and grasping the T-bar to turn the lip through $180^{\circ}$. The unnecessary pin rotations were incorporated on the assumption that participants would be unlikely to turn the pin unless this action had been demonstrated. Whiten et al. (1996) also found that children were more likely to pull the handle out than turn it.

5. Bolts box (Whiten et al. 1996, Figure 1e, $9 \mathrm{cmX} 9 \mathrm{cmX} 9 \mathrm{~cm}$ ) had a hinged lid held shut by two smooth metal rods that were removed with combined 
twisting and pulling. The bolts were not screw-threaded so they could be pulled out without twisting.

6. Fishing tube (Humayun 2006, Figure 1f) involved a $2 \mathrm{cmX} 4 \mathrm{cmX} .5 \mathrm{~cm}$ plastic box with a metal clip attached to it being dropped to the bottom of a transparent tube $(25 \mathrm{cmX} 4 \mathrm{~cm})$. A stick $(27 \mathrm{cmX} 1.5 \mathrm{~cm})$ with a hook attached to its tapered end and a magnet glued to the opposite end was inserted hook downward into the tube. In the full demonstration, the box was retrieved by turning the stick over and attaching the magnet to the metal clip.

\section{INSERT FIGURE 1 HERE}

Demonstrations and testing sessions were filmed using a camcorder mounted on a tripod. Demonstrations were presented on a laptop.

\section{Experimental Stimuli}

There were four filmed demonstrations for each test-object:

1. In full demonstrations, the third author manipulated and solved the puzzles. She stood in front of the objects, but slightly to the left so that her actions and the objects could be clearly seen. In full demonstrations of the lip-lock, levers, dome and fishing tube both the object movements and demonstrator actions could be seen. In the button's full demonstration, its movements were obscured from view because the demonstrator used her palm to press and turn. In the bolts-box, the rotations of the bolts were obscured from view by the demonstrator's gripping hand.

2. In ghost demonstrations, the test objects appeared to move without external manipulation. Lip-lock, levers, dome and fishing-tube were all operated using transparent thread. A plain card wall with two holes directly adjacent the bolts was erected behind the bolts-box. A long black screwdriver was inserted into grooves in the back of the bolts. The screwdriver was used to push and rotate the bolts out of the front of their holders. The lid was opened using thread. The back wall of the button-box was removed so that a demonstrator could duck out of sight and reach through to operate the button from behind.

3. In mime demonstrations, the demonstrator performed the same actions as in the full demonstration, but adjacent to the relevant parts of the test-objects without touching them.

4. In random demonstrations, the demonstrator lightly touched the surface of each of the objects without producing any action that resembled those used in the full demonstration.

Although children were given prizes of stickers or toys during the experimental trials, none of the boxes contained prizes in the filmed demonstrations. This was to avoid inadvertently increasing motivation in the full and ghost conditions where the end result of the demonstration was an open box.

\section{Procedure}

Each participant was tested individually in a quiet room. Prior to each trial, a prize was placed inside and then the box was closed out of the child's sight. The box was 
placed adjacent to the laptop upon which the demonstrations were presented. The four demonstrations for each box were counterbalanced across participants. Each participant experienced all 6 boxes and all 4 conditions; thus each was presented with 2 of the conditions twice. Each video demonstration was presented twice before the first one-minute trial and then once before each of two subsequent trials. Immediately after the demonstration, the experimenter explained, "You have one minute to get the prize out of the box. You can do anything you like to open the box." Each trial was recorded on videotape.

Prior to watching the recordings of the children's trials, two independent observers watched the films of each type of demonstration for each of the puzzle objects. They then evaluated each child's set of three trials for each puzzle-box, judging how much they looked like the full, mime and random demonstrations using a Likert scale ( $0=$ no match; $1=$ very poor; $2=$ poor; $3=$ fair; $4=$ good; $5=$ very good). Excellent inter-observer agreement was achieved (Spearman's $r=.927, p<.001$ ). The mean scores for all three trials on each puzzle-box were used in statistical analyses. Time to first solution for each puzzle object was also recorded.

\section{Results}

Mean and standard deviations relevant to the analyses for matching scores and times to first solution are presented in Table 2.The data were analysed using mixed two way ANOVAs with two-tailed pairwise post hoc comparisons. Since there were clear directional a-priori predictions for post hoc comparisons Bonferroni corrections were not applied.

\section{Degree of Matching to Full Demonstration}

CWA and TDC produced very similar profiles of mean matching to full demonstration scores for all the boxes across conditions (Table 2; Figure 2). Thus, there was no significant main effect of group, $\mathrm{F}(1,38)=1.87, \mathrm{p}=.668$, but there was a significant main effect of condition, $F(2.51,95.34)=32.18, p<.001$. Post hoc comparisons indicated that the children scored significantly higher in the full compared to ghost, $(p<.05)$, mime, $(p<.001)$, and random, $(p<.001)$ conditions. They also scored significantly higher in the ghost compared to mime $(\mathrm{p}<.001)$ and random $(p<.001)$ conditions and in the mime compared to random condition $(p<.01)$. There was no significant condition by group interaction, $\mathrm{F}(2.51,95.34)=0.18, \mathrm{p}=.879$.

\section{INSERT TABLE 2 AND FIGURE 2 ABOUT HERE}

The bolts and button boxes differed from the other four boxes in the sense that in the full condition the demonstrator's actions obscured object movements. Therefore, data from these two boxes were analyzed separately. Similar to the previous analysis, there was no main effect of group, $F(1,34)=0.04, p=.844$. There was a significant main effect of condition in which the children scored higher in the full compared to ghost condition on the button and bolts boxes, $F(1,34)=5.61, p<.05$, and there was no significant group by condition interaction, $F(1,38)=0.04, p=.841$.

The data from the four boxes where the demonstrator's actions did not obscure object movements (i.e., levers, lip-lock, fishing and dome) were also analyzed separately. Again, there was no significant main effect of group, however there was a trend towards the TDC producing a better match to demonstration than CWA, $\mathrm{F}(1,33)=3.09, \mathrm{p}=.088$. There was a significant main effect of condition in which children scored significantly higher in the full compared to ghost condition, 


\section{Object-related imitation in autism}

$\mathrm{F}(1,33)=10.31, \mathrm{p}<.01)$. However, there was no significant condition by group interaction, $\mathrm{F}(1,33)=0.71, \mathrm{p}=.407$.

\section{Degree of Matching to Actual Demonstration}

There was no significant main effect of group on the degree to which children matched the actual demonstrations in the mime, random and full conditions, $\mathrm{F}(1,38)=0.36, \mathrm{p}=.551$. There was a significant effect of condition, $\mathrm{F}(1,38)=36.45$, $\mathrm{p}<.001$, but no significant condition by group interaction, $\mathrm{F}(1,38)=1.56, \mathrm{p}=.219$. Children scored significantly higher in the full compared to mime $(p<.001)$ and random $(\mathrm{p}<.001)$ conditions. They showed a strong non-significant trend to score higher in the random compared to mime condition $(\mathrm{p}=.053)$.

\section{Time to Solution}

There was no significant main effect of group on the time to solution, $\mathrm{F}(1,38)=0.21, \mathrm{p}=.652$. There was a significant main effect of condition, $\mathrm{F}(2.42,92.04)=16.69, \mathrm{p}<.001$ (Fig. 3). The children solved the boxes significantly faster in the full compared to ghost $(\mathrm{p}<.01)$, mime $(\mathrm{p}<.001)$, and random $(\mathrm{p}<.001)$ conditions. They also solved the boxes faster in the ghost compared to random $(\mathrm{p}<.001)$. There was no significant difference in the times to first solution for the ghost and mime conditions $(\mathrm{p}=.228)$ or the mime and random conditions $(\mathrm{p}=.124)$. There was no significant condition by group interaction for time to first solution, $\mathrm{F}(2.42,92.04)=1.65, \mathrm{p}=.191$.

\section{INSERT FIGURE 3 HERE}

The times to first solution on the obscured object movement boxes (i.e., bolts and button) were analyzed separately. There was no significant main effect of group, $\mathrm{F}(1,34)=1.61, \mathrm{p}=.214$, or condition, $\mathrm{F}(1,34)=0.08, \mathrm{p}=, 779$, and no significant condition by group interaction, $\mathrm{F}(1,34)=0.23, \mathrm{p}=.635$. Similarly, the data from the non-obscured boxes (i.e., levers, dome, lip-lock and fishing) were analyzed separately. There was significant main effect of group, $F(1,33)=4.51, p<.05$, in which the TDC solved the boxes faster than CWA (Table 2). There was also a significant main effect of condition in which children solved the non-obscured boxes faster in the full compared to ghost condition, $F(1,33)=11.49, \mathrm{p}<.01$ (Table 2). Contrary to our predictions, there was no significant group by condition interaction, $F(1,33)=0.006$, $\mathrm{p}=.937$.

\section{Factors Predicting Imitative Performance}

A series of four multiple regressions (one for each condition: full, ghost, mime and random) were used to test if the factors diagnosis, VIQ, NVIQ, motor coordination (combined errors on the peg board and buzz wire tasks) and age significantly predicted the DV "match to full demonstration" score. All of the factors were entered into the regression in one-step, as there were no a priori predictions regarding the predictive value of each factor. There were no significant linear relationships between the children's matching scores and the combined predictive factors in the full $\left(\mathrm{F}(5,39)=0.45, \mathrm{p}=.807\right.$; adjusted $\left.\mathrm{R}^{2}=-.075\right)$, ghost $(\mathrm{F}(5,39)=2.03$, $\mathrm{p}=.099$; adjusted $\left.\mathrm{R}^{2}=.117\right)$, or random $\left(\mathrm{F}(5,39)=1.67, \mathrm{p}=.169\right.$; adjusted $\left.\mathrm{R}^{2}=-.079\right)$ conditions. However, the results revealed a significant model for the match to full demonstration data in the mime condition $\left(F(5,39)=3.66, \mathrm{p}<.01\right.$; adjusted $\left.\mathrm{R}^{2}=-.255\right)$. 
Thus, roughly $25 \%$ of the variability in children's imitation scores during the mime condition was predicted by their diagnosis, VIQ, and level of motor coordination difficulties (table 3 ).

An additional four one-step multiple regressions, one for each condition, were conducted on the DV time to first solution using the same predictive factors as previously. No significant linear relationships were found for the full $(F(5,39)=0.84$, $\mathrm{p}=.530$; adjusted $\left.\mathrm{R}^{2}=-.110\right)$, mime $\left(\mathrm{F}(5,39)=0.68, \mathrm{p}=.640\right.$; adjusted $\left.\mathrm{R}^{2}=-.042\right)$ or random $\left(\mathrm{F}(5,39)=0.96, \mathrm{p}=.456\right.$; adjusted $\left.\mathrm{R}^{2}=-.005\right)$ conditions. However, the results revealed a significant model for the match to full demonstration data in the mime condition $\left(\mathrm{F}(5,39)=3.25, \mathrm{p}<.05\right.$; adjusted $\left.\mathrm{R}^{2}=-.224\right)$. Thus, roughly $22 \%$ of the variability in children's time to solution during the ghost condition was predicted by their NVIQ, VIQ, and age (table 3).

INSERT TABLE 3 ABOUT HERE

\section{Discussion}

The aim of this study was to investigate whether rather than imitating objectrelated actions, CWA learn by alternative social learning processes such as OMR or local enhancement. CWA's and TDC's overall pattern of responding across the different conditions was very similar except that CWA tended to solve the puzzle boxes in the full and ghost conditions more slowly than TDC. Both groups of children matched most faithfully in the full condition, next closely in the ghost followed by the mime condition, and least well in the random condition. All told, the results provided no evidence that the CWA were imitating any less often or less accurately than TDC or that they were relying more on OMR or local enhancement.

OMR was distinguished from imitation primarily by comparing responses between the ghost and full conditions. The ghost condition isolated object movements from demonstrator actions. If the children were learning by OMR, then on the boxes where both object movements and demonstrator actions were clearly visible (i.e., the non-obscured levers, fish, dome and lip-lock boxes) there should have been no advantage to seeing demonstrator actions in the full condition. Despite the fact that the TDC solved the boxes faster overall in the full and ghost condition, there was no significant group by condition interaction and both groups matched more closely and solved the non-obscured boxes faster in the full compared to ghost condition. In the full condition for the obscured boxes (i.e., button and bolts), the demonstrator's actions blocked visual access to object movements. Thus, if the children were relying on OMR, they should perform significantly better in the ghost compared to full condition for these boxes. In fact, both CWA and TDC achieved higher matching scores in the full condition and there was no significant difference in the times to solution between the full and ghost conditions. These results taken together indicate that both groups of children benefitted more from being able to see and then imitate demonstrator actions compared to when they were responding to object movements alone.

The children's responses to the full and ghost condition seemed relatively unaffected by diagnosis. Diagnosis, along with age, motor coordination, verbal IQ and non-verbal IQ, failed to significantly predict the variance in matching scores or times to solution in the full condition. Similarly, neither diagnosis nor motor coordination significantly predicted the variance in matching scores or times to solution in the 
ghost condition. The only significant predictors for performance in the ghost condition were age, verbal IQ and non-verbal IQ with regards to times to solution. Regardless of diagnosis, older children or children with a higher verbal or non-verbal IQ were able to use the information gained from the ghost displays to help them solve the boxes faster. The ghost condition required children to devise appropriate actions so as to cause the objects to move in the way they saw demonstrated. Thus, we propose that ghost displays require a degree of causal reasoning which develops with age and is associated with IQ.

Whilst the ghost condition isolated object movements, the mime condition isolated demonstrator actions. In the mime demonstrations, the objects did not move while the demonstrator performed the target actions from the full demonstration adjacent to them. Both groups of children struggled to make sense of the mimes, achieving lower matching scores and slower times to solution in the mime compared to full and ghost conditions. Although the children achieved higher matching to full scores in the mime compared to random condition, they failed to solve the boxes significantly faster in the mime condition. Several children in both groups accurately reproduced mimed actions without applying them to the boxes and then seemed surprised when they proved ineffective. In order to benefit from mimed demonstrations, children needed to read the underlying communicative intent i.e., that mimed actions should be applied to the objects. It is well known that CWA struggle to make sense of non-literal communicative acts (Happé 1993). Thus, it is perhaps unsurprising that the regression analysis indicated that diagnosis and verbal IQ significantly predicted performance in the mime condition.

The random condition was not only useful as a benchmark against which to compare the mime condition; it also allowed us to test for the effect of local enhancement. The children's attention was drawn to the objects by the demonstrator performing random actions on their surface, but then to solve the puzzles they needed to devise and apply their own set of functionally appropriate actions. As expected, both groups of children performed least well in the random condition, achieving significantly lower matching scores and times to solution. As indicated by the match to actual demonstration scores, some children copied the random actions, but to a significantly lower extent than they matched actions in the full condition. However, children received higher match to actual scores in the random compared to mime condition. This is partly because if the children responded to the mimes by applying the mimed actions to the objects' surfaces (which, of course, was the appropriate response), they received a reduced match to actual score. Some children ignored the random actions and attempted to devise their own solution to the puzzles. However, contrary to our initial prediction, since there were no significant between-group differences in the match to full or actual scores, it seems the CWA did not exhibit a higher tendency than TDC to devise their own solutions. Furthermore, the fact that the children solved the boxes more slowly and achieved lower match to full scores in the random compared to full and ghost conditions suggests that they were not learning by local enhancement alone. Instead, the elevated performance in full compared to ghost and random conditions and ghost compared to random suggests that the children must have also been learning by OMR and imitation. Finally, the absence of between-group differences indicates that CWA were imitating in the same way and to the same extent as TDC.

There may be a number of reasons why we did not find an autism-specific imitative deficit in our study. One might be tempted to argue that the experimental tasks and the actions needed to solve them were too simple. However, it should be 
noted that there were no ceiling effects. The children scored well in the full condition with an average matching score of just above 4 (good). Yet the maximum score was 5 (very good). In addition, the scores in the full condition were not intended to be considered in isolation. It was the comparisons across conditions that were of prime importance, not the matching scores achieved in the full condition alone. The cross condition comparisons indicated that the CWA were imitating rather than relying exclusively on other non-imitative social learning processes.

Of course, few researchers would assume that CWA exhibit a complete inability to imitate actions on objects. It seems more reasonable to suggest that they imitate object-related activities to a lesser extent or with somewhat less fidelity compared to TDC. However, our findings are surprising because they suggest that in the context of manipulating rigid puzzle-objects with extrinsic rewards, CWA exhibit no imitative deficits. Nor was there any evidence that, compared to TDC, CWA rely more on non-social versus social aspects of demonstrations.

Three other studies have also found no obvious deficits in the imitation of goal-directed object-related actions in CWA (Hamilton et al. 2007; Nielsen \& Hudry 2010; Whiten \& Brown 1998). However, Rogers et al. (2010) found that CWA, compared with matched controls, were less likely to imitate items with a discernible end result, such as shaking a bell to make a noise or scribbling with a marker. One reason for these disparate results could be marked differences in age across the samples tested. The children tested in Rogers et al.'s study were more than half the age of the children in any of the other studies. In addition, the goals presented by Rogers et al. were somewhat arbitrary and intrinsic to the objects themselves (i.e., making noises or dents in putty). To some extent, there is little point in achieving these goals, except in terms of socially engaging with the demonstrator. In contrast, the goals in the present study were extrinsic in terms of attaining prizes. An important question for future research into imitation in autism may be; how salient is the goal over and above social engagement?

Another possible reason why imitation deficits were not observed in the present study is that the objects were rigid rather than pliable, thereby helping to counteract motor coordination effects. Several studies have found that motor coordination explains a great deal of the variance in imitative ability in CWA (e.g., Green et al. 2002; Vanvuchelen 2007, but see Zachor et al. 2010). Although the CWA in our study exhibited a motor coordination deficit in comparison to TDC, regression analyses indicated that this had no effect except in the mime condition. If the children accurately imitated the mimes, they would not have the objects to support their movements and motor coordination difficulties might be more evident. Similarly, if CWA are required to manipulate pliable objects such as cloth or putty (see Rogers et al. 2010; Hobson \& Hobson 2008) motor coordination may become a significant factor in imitative accuracy. However, with rigid objects such as the puzzle boxes, once children have seen and are committed to applying the demonstrated actions to the objects, the objects themselves could serve to shape or scaffold their manipulations. Future research into object-related imitation may benefit from systematically studying the effects of type of object, either rigid or pliable, being manipulated.

In summary, we found no autism-specific imitative deficit in an experiment that utilized rigid objects and extrinsic rewards. Our results highlight areas of possible strength in the imitative performance of CWA. By identifying the contexts in which CWA show no imitative deficits and contrasting these with the context in which they struggle to imitate, one may gain further insight into the basis of their varied profile of 
imitative performance. Our results provide tentative support for the hypothesis that the combined effects of lowered motor coordination and social engagement is key to understanding the imitative performance of CWA. Yet, clearly further research into the relationship between OMR and imitation is needed. Future studies might benefit from investigating the effect of diagnosis, age, IQ, motor coordination, intrinsic versus extrinsic goals and pliable versus rigid objects within a single factorial design.

\section{Acknowledgements}

This research was carried out with the support of the Economic and Social Research Council (award reference number RES-00022-2006). We are very grateful to all the schools, children and parents who participated in our experiments. We are indebted to Mr. Stephen Yesson and Mr. Robert Davis for constructing the test objects, Mrs. Vivienne Custance and Dr Lisa Riley for helping in data collection, and Ms. Elisabeth Martinsson and Mrs. Katherine Filer for inter-observer reliability coding. We would like to thank Dr Rory Allen for offering his statistical expertise. We are also grateful to the reviewers who provided extremely helpful and insightful commentaries on earlier versions of this paper.

\section{References}

American Psychiatric Association. (2000). DSM-IV-TR: Diagnostic and Statistical Manual of Mental Disorders (Diagnostic \& Statistical Manual of Mental Disorders (4th ed.). American Psychiatric Press Inc.

Bhat, A. N., Landa R. J., \& Galloway J. C. (2011).Current perspectives on motor functioning in infants, children, and adults with autism spectrum disorders.Physical Therapy, 91, 1116-29.

Bird, G., Leighton, J., Press, C., \&Heyes, C. (2007).Intact automatic imitation of human and robot actions in autism spectrum disorders.Proceedings of the Royal Society B,274, 3027-3031.

Bruininks, R.H. \&Bruininks, B.D. (2005). Bruininks-Oseretsky Test of MotorProficiency(2nd ed). Windsor: NFER-Nelson.

Call, J., \& Carpenter, M. (2002). Three sources of information in social learning. In K. Dautenhahn\& C. L. Nehaniv (Eds.), Imitation in animals and artifacts(pp. 211228). Cambridge, MA: MIT Press.

Custance, D. M., Whiten, A. \&Fredman, T. (1999).Social learning of an artificial fruit task in capuchin monkeys (Cebusapella).Journal of Comparative Psychology, 113, 13-23.

Dawson, M., Soulieres, I., Gernsbacher, M. A., \&Mottron, L. (2007).The level and nature of autistic intelligence.Psychological Science, 18, 657-662.

D'Sousa, L. (2004). Primate social transmission: patterns and processes. PhD thesis, Goldsmiths College.

Dunn, L1.M., Dunn, L.M., Whetton, C. and Burley, J. (1997). British Picture Vocabulary Scale2nd edition (BPVS-II). Windsor, Berks: NFER-Nelson.

Fawcett, T. W., Skinner, A. M. J. \&Goldsmith A. R. (2002). A test of imitative learning in starling using two-action method with an enhanced ghost control.Animal Behaviour, 64, 547-556.

Fournier, K.A., Hass, C.J., Naik, S.K., Lodha, N., Cauraugh, J.H. (2010). Motor coordination in autism spectrum disorders: A synthesis and meta-analysis. Journal of Autism and Developmental Disorders, 1227-40. 
Gergeley, G., Bekkering, H. \&Kiraly, I. (2002).Rational imitation in preverbal infants.Nature, 415, 755.

Green, D., Baird, G., Barnett, A. L., Henderson, L., Huber, J., \& Henderson, S. E. (2002). The severity and nature of motor impairment in Asperger's syndrome: A comparison with specific developmental disorder of motor function. Journal of Child Psychology and Psychiatry, 43, 655-668.

Hamilton, A. F. D. C., Brindley, R. M., \&Frith, U. (2007). Imitation and action understanding in autistic spectrum disorders: how valid is the hypothesis of a deficit in the mirror neuron system? Neuropsychologia, 45, 1859-68.

Happé, F. G. E. (1993). Communicative competence and theory of mind in autism: A test of relevance theory. Cognition, 48, 101-119.

Henderson, S.E., Sugden, D.A. \& Barnett, A. (2007).MovementAssessmentBattery for Children-2.2nd edition(Movement ABC-2).Examiner'smanual.London: PearsonAssessment.

Heyes, C. M. (1993).Imitation, culture and cognition.Animal Behaviour, 46, 9991010.

Hobson, R. P. \&Hobson, J. A. (2008).Dissociable aspects of imitation: a study in autism. Journal of Experimental Child Psychology, 101, 170-85.

Hobson, R. P., \& Lee, A. (1999). Imitation and identification in autism.Journal of child psychology and psychiatry, and allied disciplines, 40, 649-59.

Hopper, L. (2010). 'Ghost' experiments and the dissection of social learning in humans and animals. Biological Review Cambridge Philos Soc..

Hopper, L. M.., Flynn, E. G., Wood, L. A. N.\& Whiten, A. (2010). Observational learning of tool use in children: Investigating cultural spread through diffusion chains and learning mechanisms through ghost displays. Journal of Experimental Child Psychology, 106, 82-97.

Humayun, S. (2006). Imitation, tutoring and tool use in human infancy. $\mathrm{PhD}$ thesis, Goldsmiths College.

Ingersoll, B. (2008). The effect of context on imitation skills in children with autism.Research in Autism Spectrum Disorders, 2, 332-340.

Lord, C., Risi, S., Lambrecht, L., Cook, E. H., Leventhal, B. L., DiLavore, P. C., et al. (2000). The autism diagnostic observation schedule-generic: a standard measure of social and communication deficits associated with the spectrum of autism. Journal of Autism and Developmental Disorders, 30, 205-23.

Lord, C., Rutter, M., \&LeCouteur, A. (1994). Autism Diagnostic Inter- view-Revised: A revised version of a diagnostic interview for caregivers of individuals with possible pervasive developmental disorders. Journal of Autism and Developmental Disorders, 24, 659-685.

McDuffie, A., Turner, L., Stone, W., Yoder, P., Wolery, M., \&Ulman, T. (2007). Developmental correlates of different types of motor imitation in young children with autism spectrum disorders. Journal of Autism and Developmental Disorders, $37,401-12$.

Meltzoff, A. N. (1985). Immediate and deferred imitation in fourteen and twentymonth-old infants.Child Development, 56, 62-72.

Meltzoff, A. N. (2005). Imitation and other minds: The "Like Me" hypothesis. In S. Hurley and N. Chater (Eds.), Perspectives on Imitation: From Neuroscience to Social Science (Vol. 2, pp. 55-77). Cambridge, MA: MIT Press.

Meltzoff, A. N., \&Gopnik, A. (1993). The role of imitation in understanding persons and developing a theory of mind. In S. Baron-Cohen, H. Tager-Flusberg,\& D. J. 


\section{Object-related imitation in autism}

Cohen (Eds.), Understanding Other Minds: Perspectives from autism(pp. 335366). New York: Oxford University Press.

Nielsen, M. \&Hudry, K. (2010). Overimitation in children with autism and Down syndrome.Australian Journal of Psychology, 62, 67-74.

Perra, O., Williams, J. H. G., Whiten, A., Fraser, L., Benzie, H., \&Perrett, D. I. (2008).Imitation and 'theory of mind' competencies in discrimination of autism from other neurodevelopmental disorders.Research in Autism Spectrum Disorders, 2, 456-468.

Raven, J., Raven, J. C., \& Court, J. H. (1998). Raven Manual: Standard progressive matrices. Oxford, England: Oxford Psychologists Press.

Receveur, C., Lenoir, P., Desombre, H., Roux, S., Barthelemy, C., \&Malvy, J. (2005). Interaction and imitation deficits from infancy to 4 years of age in children with autism: a pilot study based on videotapes. Autism, 9, 69-82.

Rogers, S. J. (1999).An examination of the imitation deficit in autism. In J. Nadel, \& G. Butterworth (Eds.), Imitation in infancy (pp. 254-283). Cambridge: Cambridge University Press.

Rogers, S. J., \& Pennington, B. F. (1991). A theoretical approach to the deficits in infantile autism.Development and Psychopathology, 3, 137-162.

Rogers, S. J., Young, G. S., Cook, I., Giolzetti, A., \&Ozonoff, S. (2010). Imitating actions on objects in early-onset and regressive autism: Effects and implications of task characteristics on performance. Development and Psychopathology, 22(1), $71-85$.

Skuse, D., Warrington, R., Bishop, D., Chowdhury, U., Lau, J., Mandy, W., et al. (2004). The developmental, dimensional and diagnostic interview (3di): a novel computerized assessment for autism spectrum disorders. Journal of the American Academy of Child and Adolescent Psychiatry, 43, 548 -558.

Spence, K. W. (1937). Experimental studies of learning and the mental processes in infra-human primates. Psychological Bulletin, 34,806-850.

Subiaul, F., Vonk J. \& Rutherford, M.D. (2011). The ghosts in the computer: The role of agency and animacy attributions in "ghost controls". PLoS ONE, 6, e26429.

Tennie, C., Call, J. \&Tomasello, M. (2006). Push or pull: imitation vs. emulation in great apes and human children. Ethology, 112, 1159-1169.

Vanvuchelen, M., Roeyers, H., \& De Weerdt, W. (2007). Nature of motor imitation problems in school-aged boys with autism: A motor or a cognitive problem? Autism, 11, 225-240.

Vanvuchelen, M., Roeyers, H. \& De Weerdt, W. (2011). Imitation assessment and its utility to the diagnosis of autism: evidence from consecutive clinical preschool referrals for suspected autism. Journal of Autism and Developmental Disorders, 41, 484-496.

Whiten, A. \& Brown, J. D. (1998). Imitation and the reading of other minds:

Perspectives from the study of autism, normal children and non-human primates. In: Intersubjective communication and emotion in ontogeny, S. Bråten (Ed.), 260280. Cambridge, UK : Cambridge University Press.

Whiten, A., Custance, D. M., Gomez J-C.,Teixidor, P., \& Bard, K. A. (1996). Imitative learning of artificial fruit processing in children (Homosapiens) and chimpanzees (Pan troglodytes).Journal of Comparative Psychology, 110, 3-14.

Whiten, A., \& Ham, R. (1992). On the nature and evolution of imitation in the animal kingdom: Reappraisal of a century of research. In P. J. B. Slater, J. S. Rosenblatt, C. Beer, \& M. Milinski (Eds.), Advances in thestudy of behavior(pp. 239-283). New York: Academic Press. 


\section{Object-related imitation in autism}

Whiten, A., Horner, V., Litchfield, C.A., Marshall- Pescini, S. (2004). How do apes ape? Learning \& Behavior, 32: 36-52.

Williams, J. H. G., Whiten, A., \& Singh, T. (2004). A systematic review of action imitation in autistic spectrum disorder.Journal of Autism and Developmental Disorders, 34, 285-99.

Young, G. S., Rogers, S. J., Hutman, T., Rozga, A., Sigman, M. \&Ozonoff, S. (2011). Imitation from 12 to 24 months in autism and typical development: a longitudinal Rasch analysis. Dev. Psychol., 47, 1565-78.

Zachor, D. A., Ilanit, T., \&Itzchak, E. B. (2010).Autism severity and motor abilities correlates of imitation situations in children with autism spectrum disorders. Research in Autism Spectrum Disorders, 4, 438-443. 


\section{Object-related imitation in autism}

Table 1: Diagnostic and psychometric data for participants in experiments 1,2 and 3.

\begin{tabular}{|c|c|c|}
\hline & $\begin{array}{l}\text { Autism } \\
\text { Mean (SD) range }\end{array}$ & $\begin{array}{l}\text { Comparison } \\
\text { Mean (SD) range }\end{array}$ \\
\hline Chronological Age (months) & $124.0(27.88) \quad 86-174$ & $123.65(28.64) 83-163$ \\
\hline Verbal IQ (BPVS standardised score) & $88.3 \quad(16.7) \quad 53-110$ & $90.45 \quad(15.98) 70-137$ \\
\hline Non-verbal IQ (Raven's Matrices raw score) & $27.6 \quad(7.39) \quad 15-43$ & $28.70 \quad(9.14) \quad 12-43$ \\
\hline 3DI: & & \\
\hline Reciprocal social and interaction skills & $14.93 \quad(3.51) \quad[10-30]^{a}$ & \\
\hline Social expressiveness & $(1.19) \quad[1-4]^{a}$ & \\
\hline Language and communication skills & $14.55 \quad(3.55) \quad[8-26]^{a}$ & \\
\hline Use of gesture and non-verbal play & $\begin{array}{lll}7.39 & (2.36) & {[7-14]^{a}}\end{array}$ & \\
\hline Repetitive/stereotyped behaviors & $(2.31)[3-12]^{a}$ & \\
\hline
\end{tabular}

aFigures in square brackets indicate the range of clinical significance on each of the subscales of the 3Di (low scores indicate low ASD severity).

Table 2: Mean Likert scores and times to solution for the different combinations of boxes and conditions

\begin{tabular}{|c|c|c|c|c|c|c|c|c|}
\hline & \multicolumn{2}{|l|}{ Full } & \multicolumn{2}{|l|}{ Ghost } & \multicolumn{2}{|l|}{ Mime } & \multicolumn{2}{|c|}{ Random } \\
\hline & CWA & TDC & CWA & TDC & CWA & TDC & CWA & TDC \\
\hline Match to full (all boxes) & $\begin{array}{l}4.2 \\
(1.17)\end{array}$ & $\begin{array}{l}4.2 \\
(0.98)\end{array}$ & $\begin{array}{l}3.35 \\
(1.06)\end{array}$ & $\begin{array}{l}3.45 \\
(1.4)\end{array}$ & $\begin{array}{l}2.67 \\
(.81)\end{array}$ & $\begin{array}{l}2.46 \\
(0.94)\end{array}$ & $\begin{array}{l}1.98 \\
(1.19)\end{array}$ & $\begin{array}{l}1.84 \\
(1.03)\end{array}$ \\
\hline Times (all boxes) & $\begin{array}{l}37.35 \\
(49.23)\end{array}$ & $\begin{array}{l}16.77 \\
(14.53)\end{array}$ & $\begin{array}{l}82.83 \\
(65.33)\end{array}$ & $\begin{array}{l}58.05 \\
(64.8)\end{array}$ & $\begin{array}{l}87.38 \\
(64.2)\end{array}$ & $\begin{array}{l}92.08 \\
(66.39)\end{array}$ & $\begin{array}{l}99.25 \\
(49.18)\end{array}$ & $\begin{array}{l}122.23 \\
(61.71)\end{array}$ \\
\hline $\begin{array}{l}\text { Match to full (obscured } \\
\text { boxes) }\end{array}$ & $\begin{array}{l}4.05 \\
(.78)\end{array}$ & $\begin{array}{l}3.94 \\
(1.17)\end{array}$ & $\begin{array}{l}3.35 \\
(.6)\end{array}$ & $\begin{array}{l}3.35 \\
(.73)\end{array}$ & NA & NA & NA & NA \\
\hline Times (obscured boxes) & $\begin{array}{l}45.2 \\
(38.5)\end{array}$ & $\begin{array}{l}34.44 \\
(33.14)\end{array}$ & $\begin{array}{l}55.6 \\
(56.15)\end{array}$ & $\begin{array}{l}31.78 \\
(34.41)\end{array}$ & NA & NA & NA & NA \\
\hline $\begin{array}{l}\text { Match to full (non-obscured } \\
\text { boxes) }\end{array}$ & $\begin{array}{l}4.1 \\
(1.5)\end{array}$ & $\begin{array}{l}4.87 \\
(.21)\end{array}$ & $\begin{array}{l}3.22 \\
(1.62)\end{array}$ & $\begin{array}{l}3.37 \\
(1.55)\end{array}$ & NA & NA & NA & NA \\
\hline Times (non-obscured boxes) & $\begin{array}{l}41.41 \\
(56.47)\end{array}$ & $\begin{array}{l}13.69 \\
(14.14)\end{array}$ & $\begin{array}{l}94.09 \\
(71.92)\end{array}$ & $\begin{array}{l}63.94 \\
(75.69)\end{array}$ & NA & NA & NA & NA \\
\hline Match to actual & NA & NA & NA & NA & $\begin{array}{l}1.84 \\
(1.75)\end{array}$ & $\begin{array}{l}1.71 \\
(1.96)\end{array}$ & $\begin{array}{l}2.11 \\
(1.62)\end{array}$ & $\begin{array}{l}2.82 \\
(1.69)\end{array}$ \\
\hline
\end{tabular}

$\mathrm{NA}=$ These figures are not applicable to the hypotheses and presented analyses. 
Object-related imitation in autism

Table 3: Regression statistics for predictor variables in significant regression models

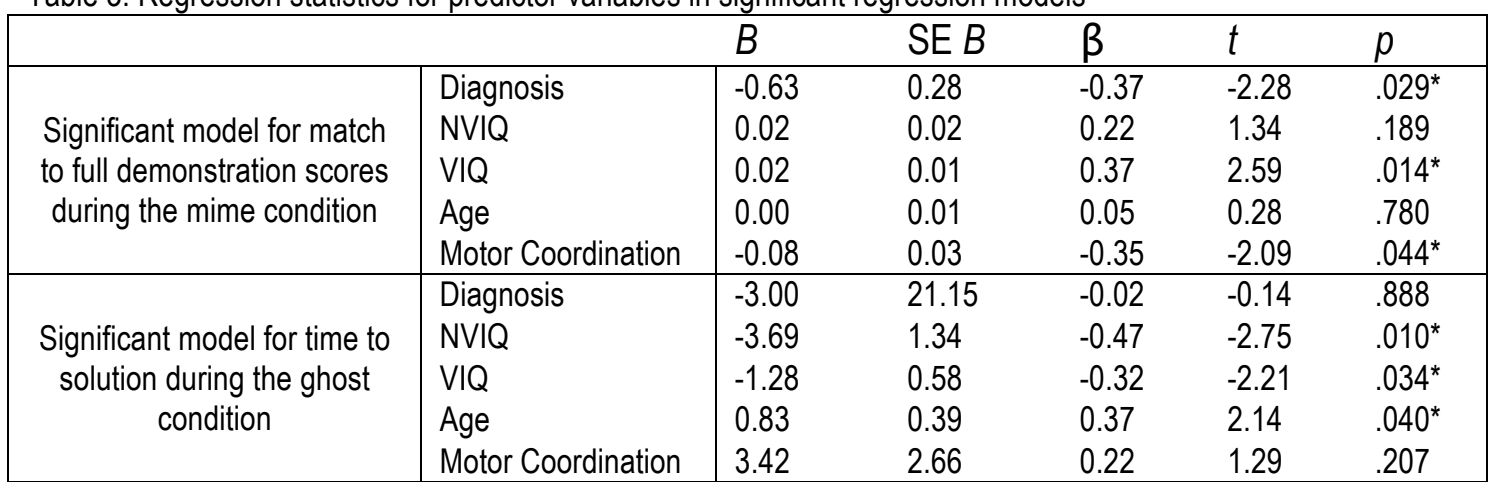

Note: $\mathrm{B}=$ un-standardised beta coefficient, $\mathrm{SE} B=$ standard error, $\beta=$ standardised beta coefficient, $\mathrm{t}=\mathrm{t}$-test statistic, $p=$ significance value 
Object-related imitation in autism

Figure 1

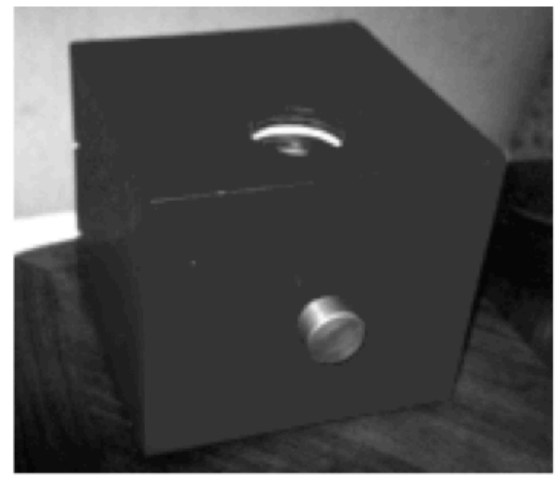

a

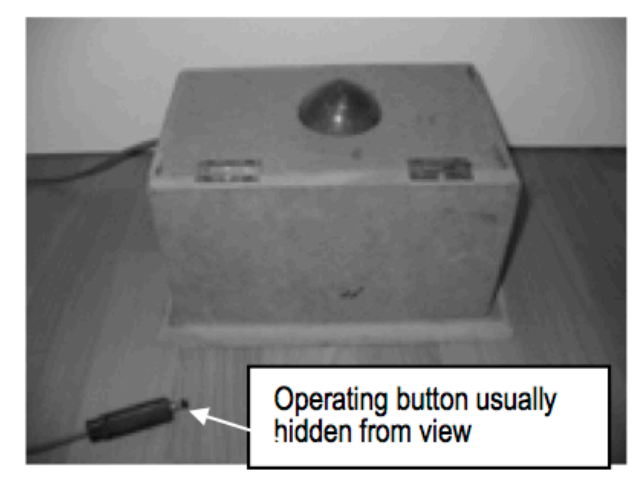

C

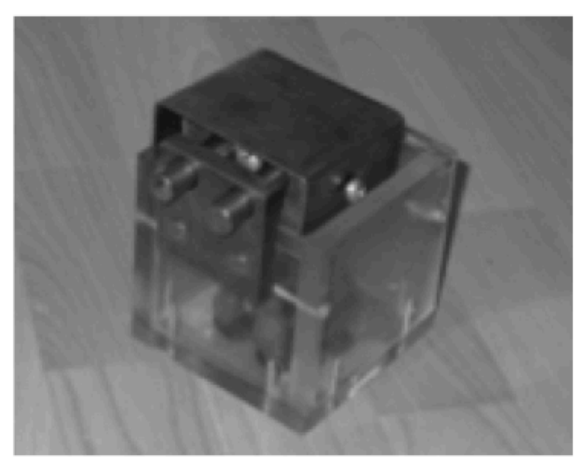

e

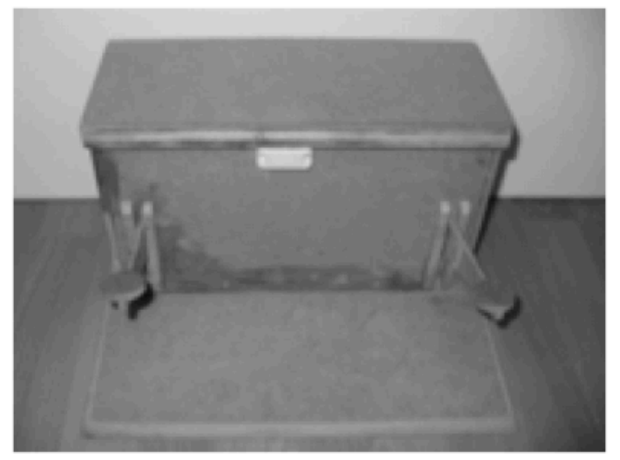

b

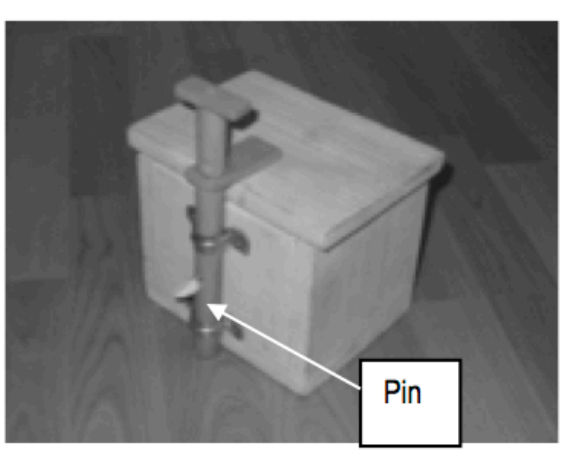

d

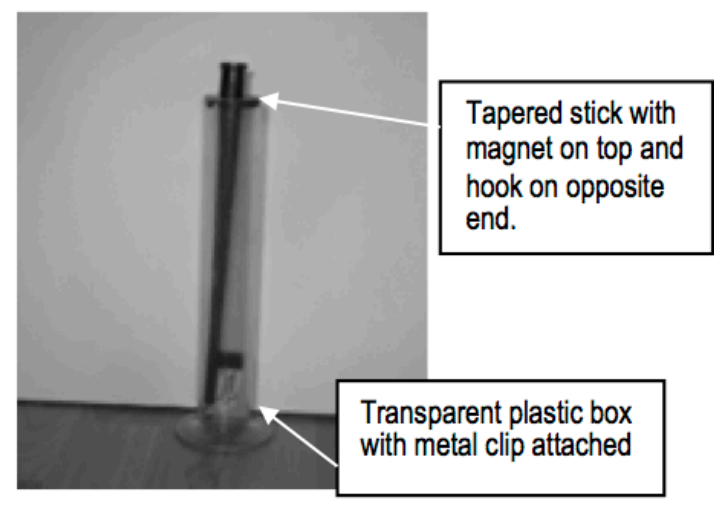

f

Figure 1: The six boxes. a) Button; b) Levers; c) Dome; d) Lip-lock; e) Bolts; f) Fishing tube 


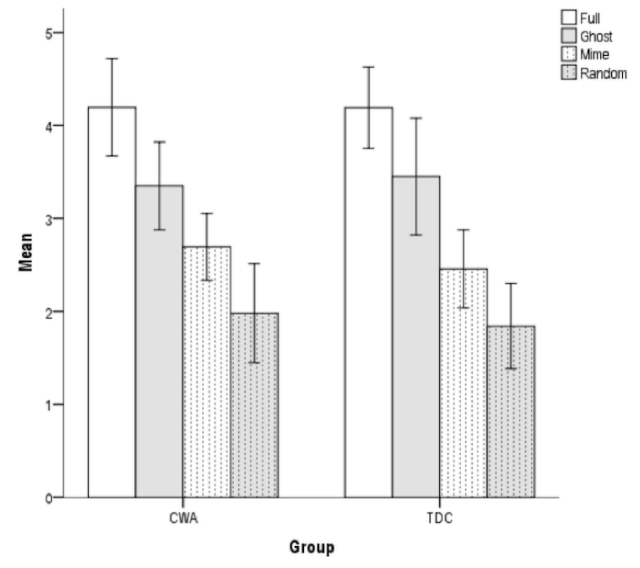

Figure 2: Mean match to full demonstration scores (based on a 0-5 Likert scale of $0=$ no match to $5=$ very good match with $+/-2$ standard error bars)

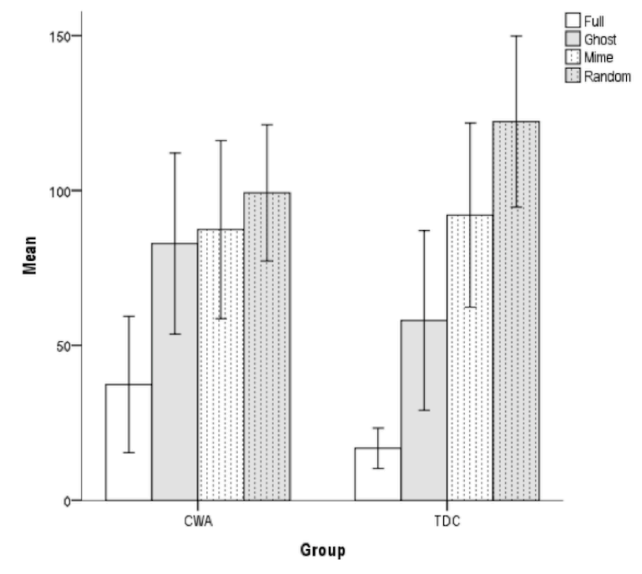

Figure 3: Mean times to first solution (time in seconds with $+/-2$ standard error bars) 